\title{
Integração curricular por áreas com extinção das disciplinas no Ensino Médio: Uma preocupante realidade não respaldada pela pesquisa em ensino de física \\ (Curriculum integration with subject extinction in secondary school education: A threatening reality not supported by research in Physics Education)
}

\author{
Erika Regina Mozena ${ }^{\mathbb{W}}$, Fernanda Ostermann \\ Instituto de Física, Universidade Federal do Rio Grande do Sul, RS, Brasil \\ Recebido em 21/10/2013; Aceito em 7/11/2013; Publicado em 6/3/2014
}

\begin{abstract}
O Ministério da Educação (MEC) tem anunciado uma integração curricular por áreas do conhecimento no Ensino Médio brasileiro sob os moldes do Exame Nacional do Ensino Médio (ENEM). Nessa mudança, as disciplinas de física, química e biologia seriam ministradas por um único professor sob a denominação de "ciências da natureza". A partir de pesquisa documental, pretendemos mostrar nesse artigo que, embora essa mudança ainda esteja em fase de discussão, ela já é uma realidade em muitas escolas, sendo perfeitamente legal sob o ponto de vista dos documentos oficiais. Tal mudança também é incentivada por uma série de políticas públicas para a educação do Governo Federal, como a ampliação do Programa Ensino Médio Inovador (ProEmi), a reformulação dos livros didáticos e a universalização do ENEM. Também mostramos nesse trabalho, a partir de revisão bibliográfica, que a interdisciplinaridade tem sido estudada e defendida pela pesquisa em ensino de física/ciências apenas em momentos específicos na sala de aula e não de maneira integrada, evidenciando que a mudança proposta pelo MEC não tem qualquer respaldo científico.
\end{abstract}

Palavras-chave: integração curricular, Ensino Médio, ensino de física.

The Ministry of Education (MEC) has announced the curriculum integration in Brazilian secondary schools by areas of knowledge as proposed by the patterns of ENEM (National Secondary Education Examination). With this change the subjects of Physics, Chemistry and Biology would be taught by a single teacher under the name of "Natural Sciences". Through documentary research we intend to show in this article that, although this change is still under discussion, it is happening in many schools, being perfectly legal from the point of view of official documents. This change is also encouraged by several public policies of the Federal Government, such as ProEMI expansion (Innovative High School Program), textbooks reformulation and ENEM universalisation. In our literature review we also show that interdisciplinarity has been studied and approved by research in Physics/Science education only during specific situations in the classroom and not in an integrated manner, showing that this change proposed by MEC has no scientific support.

Keywords: curriculum integration, secondary school, Physics Education.

\section{Introdução}

Após a divulgação dos baixos índices do IDEB para o Ensino Médio em 2011 (publicados em julho de 2012), o Ministro da Educação Aloizio Mercadante anunciou uma reconfiguração curricular. ${ }^{\square}$ A ideia seria adequar o currículo do Ensino Médio ao modelo do ENEM, cuja proposta é interdisciplinar e dividida por áreas ao invés de disciplinas. Assim, não existiriam mais as disciplinas física, biologia e química, mas a disciplina ciências naturais, que abarcaria interdisciplinarmente essas três últimas.

Essa proposta de integração curricular ${ }^{\mathbb{1}}$ procura se adequar à nova legislação educacional e sanar seríssimos

\footnotetext{
${ }^{1}$ E-mail: erikamozena@hotmail.com.

${ }^{2}$ Notícia referente à reconfiguração curricular: Eadha_de Så Paulo- 1138078 , acessado em 10/10/2013.

${ }^{3}$ Essas declarações do Ministro foram efetuadas justamente em uma época de descrença no ENEM após uma série de problemas com correções e no crescimento da "aceitação" deste por diversas instituições de ensino superior. Mais notícias: Fabha_de Så Paulo एᄑ38074, acessado em 10/10/2013.

${ }^{4}$ Estamos, em especial neste trabalho, referindo-nos à integração curricular como a unificação das disciplinas de uma mesma área com a consequente extinção das mesmas, que é o objetivo do Governo Federal com o chamado "redesenho curricular". No entanto, é preciso que fique muito claro que integração curricular pode assumir muitas outras acepções.
} 
problemas de falta de professores especialistas no Ensino Médio (e sabemos que a maior demanda no país é por professores de física), além de propiciar que os professores trabalhem em apenas uma escola. Mas há algum respaldo científico para essa mudança? O que os especialistas em ensino de física pensam sobre o assunto? Há alguma base legal para a extinção das disciplinas?

Apesar de forte indignação e algum alarde nas redes sociais, não houve qualquer protesto ou movimentos contundentes na mídia contra essas medidas, um silêncio que soa mais como descrença nas promessas radicais do Governo. Estariam educadores e professores esperando as mudanças acontecerem para depois se posicionarem?

Aparentemente as mudanças prometidas estão esquecidas, já que o ano de 2012 e 2013 já se foram e o MEC, apesar das promessas do Ministro, ainda não tomou nenhuma medida sobre o que tem sido chamado de "redesenho curricular". Será que vale a pena esperar?

Infelizmente, conforme discutiremos neste texto, sob o respaldo de pesquisa documental e da literatura sobre ensino de física/ciências, talvez já seja tarde, pois a integração curricular com extinção das disciplinas, além de ser totalmente plausível e legalmente lícita na atualidade, já está em processo de implementação no país, ao contrário do que pode parecer. E tudo isso sem qualquer protesto, debate, ou mesmo sustentação da pesquisa em ensino de física/ciências.

\section{Entendendo a interdisciplinaridade e a integração curricular}

A gradual contingência da interdisciplinaridade na educação básica é fruto da falácia da organização curricular por disciplinas tradicionais, que produz um acúmulo de informações com pouca contribuição para a vida pessoal e profissional das pessoas. Essa noção está em fase de transição e sendo estudada em todo o mundo.

Apesar de ideia promissora, não há qualquer consenso sobre a definição desse conceito. Por exemplo, a principal pesquisadora da área no Brasil, Ivani Fazenda, não tece uma única concepção de interdisciplinaridade e outros autores também a seguem, justificando que o termo não possui um sentido único e estável.

A grande maioria dos autores que se debruça sobre o tema concorda, entretanto, que a interdisciplinaridade se origina na noção de que o conhecimento é complexo e, portanto, não pode ser apreendido em sua essência por meio de suas partes. Essa mesma complexidade permite apenas vislumbrar uma de suas perspectivas por vez. A interdisciplinaridade, nesse sentido, seria uma mudança de atitude frente ao conhecimento, uma leitura mais abrangente entre essas perspectivas, na busca por uma substituição da concepção fragmentária para a unitária do ser humano.

Uma boa analogia para a compreensão da interdisciplinaridade como apreensão do conhecimento pode ser encontrada em um concerto musical: para a execução de uma sinfonia são necessárias a participação e a integração entre diversos elementos distintos e únicos: partituras, músicos, maestro, ambiente, público etc. Estes elementos podem atuar independentemente dos outros, mas o concerto apenas ocorre de maneira perfeita na integração e harmonização entre a atuação de todos. Da mesma maneira, o conhecimento, para ser compreendido (ou executado como um projeto), requer diversos componentes independentes (disciplinas ou áreas) atuando de maneira integrada e harmônica [1].

No entanto, esses discursos teóricos estão ainda longe da realidade prática da sala de aula. Conforme revisão bibliográfica que realizamos, a interdisciplinaridade passível de ser efetuada na escola de Ensino Médio é aquela compreendida como o diálogo, a relação e a negociação entre um ou mais conhecimentos disciplinares, não necessariamente apenas os tradicionais (ou seja, não apenas física, química, história, geografia, mas também a ética, a cidadania, a jurisdição, a medicina, a engenharia etc).

Nesse sentido, a interdisciplinaridade pode ser efetivada na sala de aula por um único professor, quando este revela os limites da sua disciplina e aborda os conteúdos sob o referencial de outras matérias, ${ }^{\mathbf{Q}}$ ou pode ainda ser desenvolvida numa metodologia pautada em projetos por vários professores (embora isso possa significar ações bem diferentes).

Também a interdisciplinaridade não constitui a negação ou extinção das disciplinas, nem o cruzamento (ou superposição) das mesmas, a chamada multidisciplinaridade [2].

A interdisciplinaridade tem sido usada nas pesquisas em ensino de física/ciências para esclarecer uma situação (como "no escuro todos os gatos são pardos" [3]), resolver um problema (por exemplo: "como um banho pode ser saudável?" [5]) ou mesmo compreender algo em seu contexto mais próximo e possível do real (exemplo: "aquecimento global e implicações socioam-

\footnotetext{
${ }^{5}$ Exemplo: quando o professor de física não se restringe apenas a ensinar som da perspectiva da física, como a sua produção e propagação, mas também do ponto de vista biológico, analisando o funcionamento do aparelho auditivo e como o nosso organismo capta as ondas sonoras e interpreta esse sinal. Tudo isso numa abordagem em que os limites da física e da biologia, para a compreensão do fenômeno, são definidos e esmiuçados.

${ }^{6}$ Em Mozena e Ostermann (2013), mostramos como os professores do Ensino Médio não trabalham interdisciplinarmente, eles apenas escolhem um tema, como "copa do mundo", e cada professor, em sua sala de aula, aborda o tema sem qualquer relação com as outras disciplinas, como geografia "África", biologia "origem do homem na África", sociologia: "apartheid", química "doping", física "física do futebol". Isso se chama multidisciplinaridade, em que não há inter-relações entre as disciplinas, e não é classificado como interdisciplinaridade.
} 
bientais de modelos de transporte") [5].

Assim, interdisciplinaridade nesta vertente e como entendida neste artigo, não se configura em extinção de especialidades, mas na sua inter-relação, a ser abordada em momentos esporádicos e específicos do currículo escolar no Ensino Médio.

Já quando nos referimos aqui à integração curricular, entendemo-la também como uma abordagem interdisciplinar, mas que vai além, pois nesse caso as disciplinas são extintas, passando então a serem ministradas de maneira integrada por área. O ensino passa então a ser totalmente focado em "temas" que abrangem os conhecimentos disciplinares da área, mas de maneira sempre integrada.

\section{Pesquisa documental sobre a inter- disciplinaridade e a integração curri- cular}

Realizamos detalhada pesquisa em documentos oficiais da área de educação e notícias veiculadas na mídia para entender quais disciplinas são obrigatórias no Ensino Médio e se existe alguma base legal para uma mudança curricular pautada na integração por áreas. Chegamos a algumas constatações importantes e preocupantes sobre a consagração da interdisciplinaridade e da integração curricular no sistema educacional brasileiro.

As novas Diretrizes Nacionais para o Ensino Médio (DCNEM) [6], homologadas em janeiro de 2012 no Governo Dilma, pautam-se no trabalho como princípio educativo e na pesquisa como princípio pedagógico. Nessa perspectiva, desaparecem do cenário nacional as noções de "competências" e "habilidades", currículo continua organizado por áreas do conhecimento (Linguagens, Matemática, Ciências Naturais e Ciências Humanas). ${ }^{\boldsymbol{}}$

Como já acontecia nas DCNEM (1998), no novo documento não há qualquer especificidade ou obrigatoriedade com relação às disciplinas que devem ser estudadas pelos nossos jovens. Apenas é imposta uma série enorme dos chamados "componentes curriculares" obrigatórios, entre eles a física, que devem ser tratados em uma ou mais áreas do conhecimento. Como está bem claro nesse documento, esses componentes curriculares ${ }^{\mathbf{q}}$ não precisam necessariamente ser ofertados como disciplina.

Os componentes curriculares que integram as áreas de conhecimento podem ser tratados ou como disciplinas, sempre de forma integrada, ou como unidades de estudo, módulos, atividades, práticas e projetos contextualizados e interdisciplinares ou diversamente articuladores de saberes, desenvolvimento transversal de temas, ou outras formas de organização. [7]

Nota-se, no trecho acima, um forte apelo à interdisciplinaridade, que nesse documento muda radicalmente de patamar em relação às DCNEM (1998). Antes, ela era compreendida como um "princípio pedagógico" e agora, nas DCNEM (2012), é fundamentada como "base da organização do Ensino Médio".

Assim, a interdisciplinaridade não está apenas institucionalizada em nossa legislação educacional, como

\footnotetext{
${ }^{7}$ No entanto, o ENEM ainda se pauta nas concepções de "competências" e "habilidades", conforme pode ser constatado na sua matriz de referência que data do ano de 2009 e ainda não foi modificada: http://portal.mec.gov.br/index.php?option=com_docman\&task= doc_download\&gid=841\&Itemid acessado em 10/10/2013.

${ }^{8}$ Nas DCNEM (1998), a Matemática e as Ciências da Natureza perfaziam uma única área.

${ }^{9}$ Segundo as DCNEM (2012), devem obrigatoriamente ser tratados em uma ou mais áreas do conhecimento no Ensino Médio:

"I. Linguagens:

a) Língua Portuguesa;

b) Língua Materna, para populações indígenas;

c) Língua Estrangeira moderna;

d) Arte em suas diferentes linguagens: cênicas, plásticas e, obrigatoriamente a musical;

e) Educação Física;

II. Matemática.

III. Ciências da Natureza:

a) Biologia;

b) Física;

c) Química.

IV. Ciências Humanas:

a) História;

b) Geografia;

c) Filosofia;

d) Sociologia." (Artigo 9 $9^{\circ}$ parágrafo único.)

E como se já não bastasse, existem outros componentes curriculares que devem ser obrigatoriamente tratados em uma ou mais áreas do conhecimento no Ensino Médio, por força de leis em vigor, como: a) Da LDB: História do Brasil (no que se refere ao estudo das culturas e etnias em sua formação) e História e Cultura Afro-brasileira e Indígena, Princípios da Proteção, Defesa Civil e a Educação Ambiental, além de Filosofia e Sociologia, que são obrigatórias em todos os anos. b) Outras leis: Língua Espanhola (obrigatoriamente ofertada, mas eletivamente efetivada), Educação Alimentar e Nutricional, Respeito e Valorização do Idoso, Educação Ambiental, Educação para o Trânsito, Educação em Direitos Humanos.

${ }^{10}$ Ainda parece que não há satisfação com a quantidade de conteúdos a serem estudados no Ensino Médio, pois aparecem cada vez mais projetos. Estes foram vetados: http://www.consed.org.br/index.php/comunicacao/noticias/ 591-comlssao-de-educacao-do-senado-rejelta-projetos-de-lel-sobre-novas-disclpIInas acessado em 10/10/2013.
} 
também tem caráter obrigatório, conforme as Diretrizes Curriculares Nacionais Gerais da Educação Básica promulgadas em 2010, que impõem que $20 \%$ da carga horária anual seja destinada para programas e projetos interdisciplinares eletivos.

Art. 17. No Ensino Fundamental e no Ensino Médio, destinar-se-ão, pelo menos, 20\% do total da carga horária anual ao conjunto de programas e projetos interdisciplinares eletivos criados pela escola, previsto no projeto pedagógico, de modo que os estudantes do Ensino Fundamental e do Médio possam escolher aquele programa ou projeto com que se identifiquem e que lhes permita melhor lidar com o conhecimento e a experiência.

Parágrafo $1^{\circ}$ Tais programas e projetos devem ser desenvolvidos de modo dinâmico, criativo e flexível, em articulação com a comunidade em que a escola esteja inserida. Parágrafo $2^{\circ} \mathrm{A}$ interdisciplinaridade e a contextualização devem assegurar a transversalidade do conhecimento de diferentes disciplinas e eixos temáticos, perpassando todo o currículo e propiciando a interlocução entre saberes e os diferentes campos do conhecimento. [8]

Ou seja, mesmo sem qualquer fundamentação teórica ou indicação prática de como efetivá-la, a interdisciplinaridade passou a ser obrigatória no ensino básico brasileiro e deve fazer parte de um novo currículo que está sendo organizado de maneira não transparente pelo Governo, $\square$ baseado nos "direitos de aprendizagem". Os documentos oficiais não tratam explicitamente do assunto "integração curricular", mas como especificam que o currículo deve ser organizado por áreas, não há qualquer empecilho legal para a extinção da disciplina de física nas escolas brasileiras, por exemplo, desde que se mantenha a área de "ciências da natureza" no currículo.

\section{Análise das políticas públicas em prol da integração curricular}

Pelo exposto até então, mostramos que a integração curricular com extinção das disciplinas é perfeitamente possível e legal em nosso sistema de ensino. Embora ainda não efetivada de maneira formal no Brasil, essa integração está em tramitação, conforme pesquisa que realizamos em notícias veiculadas pela mídia e em documentos oficiais veiculados em sites institucionais (MEC, Consed etc).

Enquanto a aprovação do novo Plano Nacional de Educação (PNE) não se efetiva, o MEC encaminhou para debate no Conselho Nacional de Secretários de Educação (Consed) uma proposta ${ }^{\mathbb{W}}$ de alteração no Ensino Médio, nomeada de "Compromisso Nacional pelo Ensino Médio", que aborda a integração entre as dis-

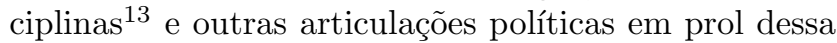
integração: o aperfeiçoamento do livro didático e a ampliação do Programa Ensino Médio Inovador (ProEMI).

Sobre o aperfeiçoamento do livro didático, no documento "Propostas Para o Ensino Médio" vinculado na página do Consed, nota-se claramente a integração curricular como uma meta nos livros didáticos, pois se considera importante a realização de ações referentes a:

Promover a revisão do Programa Nacional do Livro Didático, contemplando as mudanças propostas neste documento, com foco em áreas do conhecimento e direitos de aprendizagem, caminhando progressivamente para conteúdos digitais e garantindo a compra de livros cujo conteúdo apresente claramente uma abordagem multidisciplinar da disciplina em pauta. [9]

Com relação à ampliação do Programa Ensino Médio Inovador (ProEMI), vemos que o Governo Federal está literalmente implementando e financiando a integração curricular. E tudo isso sem qualquer respaldo ou orientação às escolas ou professores do que se entende por interdisciplinaridade ou integração curricular e como efetivá-la na prática.

O ProEMI foi lançado em 2009 e, na época, oferecia recursos financeiros às escolas que se propusessem a elaborar e a desenvolver o que foi chamado então de

\footnotetext{
${ }^{11}$ Este novo documento seria substituto aos Parâmetros Curriculares Nacionais do Ensino Médio (PCNEM). Para as séries iniciais do ensino fundamental, já está em discussão pública o novo documento, disponível em: http://portal.mec.gov.br/index.php?option=com_ content\&view=article\&id=18543:direitos-de-aprendizagem-do-ciclo-de-alfabetizacao-do-ensino-fundamental\&catid=323: orgaos-vinculados acessado em 10/10/2013. Embora corram boatos sobre o empreendimento de mesma envergadura para o Ensino Médio, não há nada oficial veiculado na página do MEC.

${ }^{12}$ Notícia disponível em: http://portal.mec.gov.br/index.php?option=com_content\&view=article\&id=19017: ministro-leva-a-camara-desafios-do-ensıno-medio-e-planos-de-reformulacao\&catid=211 acessado em 10/10/2013.

13 “A proposta do ministro constitui o Compromisso Nacional pelo Ensino Médio e inclui, entre outras medidas, ações para suprir falta de professores, para formação docente, ampliação de programas como o Programa Institucional de Bolsa de Iniciação à Docência (Pibid), ampliação da oferta de Escola de Tempo Integral, implantação de laboratórios de Química, Física, Biologia e Matemática, ampliação do Programa Ensino Médio Inovador (ProEMI), redesenho curricular, programa de adequação idade/ano para jovens de 15 a 17 anos retidos no Ensino Fundamental, aperfeiçoamento do livro didático, distribuição de tablets e outras tecnologias a professores, ampliação de laboratórios de informática, criação de bolsas de iniciação científica para alunos". http://www.consed.org.br/index.php/comunicacao/ noticias/701-consed-realizou-reuniao-com-responsaveis-pelo-ensino-medio-nos-estados acessado em $10 / 10 / 2013$.
} 
"projetos de reestruturação curricular para o Ensino Médio". Entre as exigências iniciais desse programa, estavam a carga horária mínima total de 3000 horas (600 a mais do que o obrigatório em lei) e a oferta de atividades optativas.

Em 2011, o MEC publicou um documento orientador do ProEMI, em que especifica melhor que a oferta de atividades optativas deve acontecer de acordo com os "macrocampos" (Acompanhamento Pedagógico, Iniciação Científica e pesquisa, Cultura Corporal, Cultura e Artes, Comunicação e Uso de Mídias, Cultura Digital, Participação Estudantil, Leitura e Letramento), os quais podiam estar estruturados em disciplinas, ou em outras práticas pedagógicas multi ou interdisciplinares, além de que deveriam promover a participação dos alunos no ENEM.

Em 2013, publica-se um novo documento orientador do ProEmi, no qual aparece, pela primeira vez, o termo "redesenho curricular" que, segundo o texto, deve se pautar nas Diretrizes Curriculares Nacionais para o Ensino Médio (2012) e no Plano Nacional de Educação (PNE). É muito interessante e preocupante observar que, neste documento, aparecem novas resoluções para o ProEMI. Entre elas, temos uma flexibilização da carga horária, o foco nas áreas do conhecimento e a exigência de participação no ENEM:

a) Carga horária mínima de 3.000 (três mil horas), entendendo-se 2.400 horas obrigatórias, acrescidas de 600 horas a serem implantadas de forma gradativa;

b) Foco em ações elaboradas a partir das áreas de conhecimento, conforme proposto nas Diretrizes Curriculares Nacionais para o Ensino Médio e que são orientadoras das avaliações do ENEM;

(...)

j) Oferta de ações que poderão estar estruturadas em práticas pedagógicas multi ou interdisciplinares, articulando conteúdos de diferentes componentes curriculares de uma ou mais áreas do conhecimento;

(...)

m) Participação dos estudantes no Exame Nacional do Ensino Médio (ENEM);" [10]

Essa ampliação que vem sofrendo o ProEMI também evidencia outra aposta do governo para firmar a integração: o ENEM (Exame Nacional do Ensino Médio), que foi criado em 1998 com o objetivo de avaliar o desempenho dos estudantes ao fim da educação básica e a partir de 2009, passou a ser utilizado como seleção para o ingresso no ensino superior e, segundo sua página na Internet, para "induzir a reestruturação dos currículos do Ensino Médio" ㄸ口

As provas do ENEM não são realizadas por disciplinas, mas por áreas, de maneira a fomentar uma compreensão interdisciplinar do conhecimento. No entanto, trabalhos como os de Pinheiro e Ostermann [11], Hipólito e Silveira [12] e Miranda [13] têm mostrado que a interdisciplinaridade aparece muito pouco no exame nos últimos anos.

Talvez, nessa mesma perspectiva de "preparar o terreno" para a integração curricular por áreas no Ensino Médio, o Governo Federal vem também pressionando as universidades federais que não aderiram ao ENEM, como a UFRGS,, a fazê-lo.

Dessa maneira, através do ProEMI, o Governo Federal está patrocinando, em consonância com os Estados, "experiências inovadoras curriculares", sendo, portanto, completamente lícito às escolas extinguirem suas disciplinas e ensinarem apenas focados nas áreas do conhecimento. A partir de uma rápida busca na Internet com a palavra-chave "redesenho curricular", encontramos muitos projetos de secretarias e/ou escolas em busca do apoio financeiro prometido, mostrando que a integração curricular não é apenas uma promessa, ela já está acontecendo em nossas escolas.

Com essas articulações, atenuam-se os problemas de falta de professores especialistas, as escolas melhoram sua infraestrutura com o dinheiro recebido do Governo Federal, mas os Governos Estaduais omitem esses fatos em suas propagandas.

E tudo isso sem qualquer fundamentação sobre o que é essa integração, sem qualquer respaldo das pesquisas em ensino e sem especificar parâmetros de garantia de qualidade nesse ensino. É realmente preocupante o cenário com o qual nos deparamos.

\section{A integração curricular por áreas na pesquisa em ensino de física}

Pensando especificamente nas pesquisas em ensino de física e ciências, e em quais os resultados que elas apresentam para o Ensino Médio: qual é melhor, o ensino disciplinar ou um ensino estruturado em áreas, o chamado ensino integrado, como almejado pelo Governo Federal na sua proposta de redesenho curricular?

Sem nos determos nos problemas intrínsecos a essa questão, como o próprio entendimento do que é a interdisciplinaridade, não encontramos na literatura específica sobre ensino de ciências, ${ }^{\mathbb{6}}$ com destaque para a física, qualquer trabalho contundente que nos permita responder a essa questão [14].

Existem teóricos defendendo e argumentando a favor da interdisciplinaridade escolar, outros apenas refletindo em como efetivá-la e muitas pesquisas práticas

\footnotetext{
14 http://inep.gov.br/web/enem/sobre-o-enem, acessado em 10/10/2013.

${ }^{15}$ Notícia relacionada ao caso: http://jcrs.uol.com.br/site/noticia.php?codn=134621 acessado em 10/10/2013.

${ }^{16}$ Pesquisa realizada em 44 Revistas Qualis A1 e A2 da área de Ensino e nos últimos eventos da área EPEF (Encontro de Pesquisa em Ensino de Física) e ENPEC (Encontro Nacional de Pesquisa em Ensino de Ciências).
} 
envolvendo situações pontuais interdisciplinares na escola e no currículo, em momentos específicos apenas, trabalhos esses que não nos permitem generalizações para rechaçar ou aceitar um currículo por área.

A integração curricular por áreas com extinção das disciplinas não é defendida na nossa área, sendo muito pouco discutida. Já a interdisciplinaridade se mostrou unanimidade na revisão de literatura que fizemos, sendo aprovada e julgada necessária por todos os 112 trabalhos analisados que publicaram sobre esse tema em revistas Qualis (nacionais e internacionais) da área de ensino e eventos nacionais. Especificamente sobre a integração curricular com o significado de união de disciplinas de uma mesma área, encontramos em nossa revisão bibliográfica apenas quatro trabalhos que explicitamente abordam o tema, todos eles antigos. Três desses trabalhos defendem a manutenção das disciplinas: Arcà e Vicentini [15], Lavaqui e Batista [16] e Kawamura [17], e apenas um único trabalho defende a integração na área de Ciências da Natureza, mas preservando, de certa maneira, as especificidades de cada disciplina: Bardeen e Lederman [18].

Analisando esses quatro trabalhos, percebemos que a escolha pelo uso da interdisciplinaridade em momentos esporádicos ou num currículo integrado está estritamente relacionada com os objetivos educacionais do professor.

Essa questão foi bem abordada por Lavaqui e Batista (2007), os quais julgam que a ideia de unidades didáticas integradas" "direcionam-se mais intensamente para uma formação em que os conteúdos curriculares possam ser entendidos pelos alunos de forma ampla, destacando, dentre outros aspectos, o reconhecimento das influências sociais, econômicas e culturais presentes na construção do conhecimento", ao passo que na manutenção das disciplinas e no uso de estratégias interdisciplinares esporádicas, formativos estão, na sua formulação inicial, direcionados à geração da alfabetização científica e tecnológica, constituindo-se primordialmente no estudo, sob diferentes enfoques, de questões técnico-científicas" [19].

Os autores citados defendem a utilização da interdisciplinaridade em momentos específicos, como a maioria dos trabalhos na área faz, não necessariamente defendendo uma posição contra a integração. No entanto, as justificativas apresentadas por esses autores se relacionam mais aos problemas estruturais do Ensino Médio, como a formação disciplinar dos professores e a falta de tempo para planejamento, dificuldades que de certa maneira encontram uma "solução" no redesenho curricular proposto atualmente pelo Governo Federal.

Considerando inicialmente as unidades didáticas integradas, verificamos que estas exigem uma articulação bastante ampla e

\footnotetext{
${ }^{17}$ Uma integração curricular proposta por Jurjo Torres Santomé.
}

${ }^{18}$ Como nas ilhas de racionalidade propostas por Gerard Fourez. que encontrariam fortes limitações, sobretudo em relação à formação dos professores (notadamente disciplinar) - e à dedicação para o planejamento escolar desses professores (tempo adequado para planejamento e acompanhamento de ações). Na estrutura atual de organização curricular e administrativa do Ensino Médio, é quase impeditivo o equacionamento do tempo e do espaço escolares de forma amplamente flexível para que se possa planejar e desenvolver adequadamente tal proposta.

A partir de raciocínio semelhante, Arcà e Vicentini (1981) defendem a manutenção das disciplinas e o uso da interdisciplinaridade em situações específicas. Para esses autores, o objetivo da interdisciplinaridade é levar as pessoas a compreenderem o significado e a importância dos diferentes campos disciplinares, assim como o desenvolvimento da capacidade de reconhecer e utilizar esse conhecimento disciplinar para a solução de problemas reais. Isso pode ser feito na escola, integrando noções e metodologias e empregando uma linguagem comum que pode ser entendida e usada por não cientistas. Nesse sentido, a disciplina é importante para estabelecer essas fronteiras.

Os autores também não concordam com a ideia de uma disciplina chamada "ciência integrada", mas sim com o estudo sistemático de problemas que requerem a confluência e convergência de diferentes pontos de vista disciplinares e de áreas diferentes, como a compreensão de quando a física é necessária ou o que significa olhar para um problema do ponto de vista de um físico, por exemplo. Sobre o ensino secundário, os autores frisam que o ensino deve centrar-se na compreensão do significado das disciplinas e na importância de levar seus estudantes a uma apreciação deste tipo de conhecimento, e emitir julgamentos sobre sua plenitude e relevância para a realidade.

Numa mesma linha de pensamento, com relação à importância da disciplinaridade para se desvelarem no ensino os limites da física, Kawamura defende a disciplinaridade, pois:

A ideia de disciplinaridade é importante para demarcar e para poder compor. Somente é possível compor um todo juntando as partes quando você conhece as partes. A disciplinaridade é o ato de conhecer essas partes. Um todo é muito mais que a soma das partes, mas é preciso que você tenha essas partes. [20]

Nesse caso, para a autora, não é preciso apenas ensinar a física, mas mostrar o que é a física, sua maneira de olhar o mundo e sua relação com o contexto social e 
relações de poder. Nesse caso, a disciplinaridade "permite justamente separar os limites entre o saber disciplinar e as esferas de ação/decisão. Permite explicitar o espaço de escolhas possíveis, para além das certezas da ciência."

Já com relação à defesa de um ensino integrado por áreas, Bardeen e Lederman (1998), de acordo com as demandas nos EUA, ${ }^{\mathbb{W}}$ propõem que a ciência seja ensinada de maneira integrada no Ensino Médio, mas preservando de certa maneira as especificidades de cada disciplina. Partindo de um estudo que indica que a química é pré-requisito para a aprendizagem da biologia e de que a física é pré-requisito da aprendizagem da química, os autores propõem que, em três anos, sejam ensinadas as disciplinas Ciências I, II e III, cuja ênfase no primeiro ano seria a física, no segundo, a química e, no terceiro, a biologia. Estas disciplinas seriam integradas e conjugadas com a de matemática. Os autores ainda sugerem que tópicos em ciências da Terra e do espaço podem servir como uma linha temática que usa os conhecimentos da física, química e biologia. Por exemplo, a química da atmosfera superior, a solubilidade do oceano, a fotossíntese, a rotação da Terra, a gravidade, as fontes de energia interna e externa etc.

Segundo os últimos autores citados, a proposta estava sendo aplicada em 24 escolas dos EUA. Em conversa por e-mail com a autora principal em agosto de 2013, fomos informados que o projeto acabou, embora ainda esteja sendo implementado em algumas escolas. As principais razões apontadas para seu fracasso são mudanças políticas na universidade e o fato de que os professores não se fixam por muito tempo nas escolas.

Embora este último trabalho citado defenda a integração do ensino de ciências em uma única disciplina, consideramos esta proposta viável no contexto brasileiro, pois esta abordagem não negligencia a integridade e a coerência da física como uma disciplina, o mesmo acontecendo para a química e a biologia, pois cada especialista assume a docência em um ano letivo, assessorado pelos outros professores da área. Nessa perspectiva, seria possível aliar a interdisciplinaridade obrigatória em lei com o ensino disciplinar dado por especialistas ao longo dos três anos do Ensino Médio.

\section{Discussões e conclusões}

Como procuramos mostrar neste trabalho, a partir de uma revisão bibliográfica, a extinção das disciplinas com a integração curricular por área não é defendida na área de ensino de física/ciências no Brasil. Não há qualquer respaldo científico para se efetivar uma integração por áreas nas nossas escolas secundárias.

Conseguimos vislumbrar que um esquema como tal sanaria o problema da demanda por professores específicos, propiciando condições para o professor estar vinculado a apenas uma escola e, dessa maneira, ter tempo para planejamento e maior interação com outros professores. Seguindo o mesmo raciocínio, se o ENEM e os livros didáticos se adequassem melhor ao trabalho interdisciplinar, poderíamos acabar de uma vez por todas com um Ensino Médio propedêutico apenas focado em listas enormes de conteúdos (numa linha em que se almeja ensinar menos, mas com qualidade).

No entanto, como acreditar em mudanças positivas sem qualquer respaldo científico? Sem estudos profundos de viabilidade de uma nova configuração curricular? Sem um debate amplo e transparente na sociedade e na mídia? E com professores mal remunerados, não valorizados e não preparados para trabalhar interdisciplinarmente?

Não é segredo o fato de que os nossos professores de física do Ensino Médio não estão em sua maioria preparados para reconhecer e utilizar os seus conhecimentos de base para a solução de problemas reais, o que dizer então sobre aqueles pertinentes à química e à biologia? $\mathrm{O}$ que aconteceria, então, num ambiente de redesenho curricular como aquele em que o Governo Federal está articulando?

Não nos parece estranho pensar que, com o redesenho curricular, os professores da área de ciências da natureza nas escolas públicas vão continuar trabalhando em suas salas de aulas apenas as suas especificidades de base, deixando a física de lado, o que pode levar os novos livros didáticos, a exemplo do que acontece no ensino fundamental, a privilegiar os conhecimentos de biologia, já que o desconforto com o ensino de física não passaria despercebido pelas editoras. Será o início do fim da tão temida disciplina de física? E vamos continuar esperando as mudanças acontecerem?

Procuramos também, com este trabalho, por meio de pesquisa documental, alertar para o fato de que a integração curricular, apesar de não ter sido adequadamente pensada nem estudada na área de ensino de física do nível médio, não está apenas na promessa ou em processo de fomento pelos órgãos competentes: $a$ integração curricular já é uma realidade nas escolas brasileiras, tanto do ponto de vista legal, quanto prático, uma vez que o Governo Federal, através do ProEmi, está financiando mudanças nas escolas brasileiras, além de promover outras políticas públicas ligadas ao ENEM e à reformulação dos livros didáticos que reforçam a integração curricular.

Como ainda não temos livros didáticos adequados e nem mesmo no ENEM a interdisciplinaridade é julgada apropriada, esse papel de integração caberá aos professores, em sua maioria não formados em física e que não estão preparados para o ensino interdisciplinar. Será mesmo este o destino que queremos?

\footnotetext{
${ }^{19}$ No ensino secundário nos EUA, as disciplinas de física e química costumam ser eletivas.
} 


\section{Referências}

[1] S.L. Ferreira, Práticas Interdisciplinares na Escola (Cortez, São Paulo, 2011), p. 33.

[2] E.R. Mozena e F. Ostermann, Investigando discursos e saberes experienciais dos professores de ciências sobre a interdisciplinaridade no ensino público secundário no Rio Grande do Sul (Brasil). IX Congreso Internacional sobre Investigación en Didáctica de las Ciencias, Girona, 2013. http://congres.manners.es/congres_ciencia/ gestio/creacioCD/cd/articulos/art_292.pdf, acessado em novembro de 2013.

[3] K.R. Halmenschlagerand e C.A. Souza, Investigações em Ensino de Ciências 7, 367 (2012).

[4] C.M. Nehring, C.C. Silva, J.A.O. Trindade, M. Pietrocola, R.C.M. Leite e T.F. Pinheiro, Ensaio 2, 1 (2002).

[5] S. Hunscheand y D. Auler, Revista Electrónica de Enseñanza de las Ciencias 11, 1 (2012).

[6] D.O.U., resolução $\mathrm{n}^{\circ}$ 2, de 30 de janeiro 2012. Disponível em http://portal.mec.gov.br/index. php?option=com_content\&view=article\&id= [7417\&Ltemid=866, acessado em 10/10/2013.

[7] DCNEM, 2012, op. cit., artigo 14.

[8] DCNGEB, 2010. http://portal.mec.gov.br/index. php?option=com_docman\&task=doc_download\&g1d= 6r04\&Item1al, acessado em 10/10/2013.

[9] Propostas para o Ensino Médio, p. 10. Não há data nesse documento. http://www.consed.org.br/index. php/downloads/category/3-documentos?download= $172\{\%\} 3$ Apropostas-para-avancos-ensino-medio, acessado em 10/10/2013.
[10] Documento Orientador ProEmi, 2013, p.11. http://portal.mec.gov.br/index.php?optiona com_docman\&task=doc_download\&gid=13249\&1temid, acessado em 10/10/2013.

[11] N. Pinheiro and F. Ostermann, XII EPEF, Águas de Lindóia, 2010. http://www.if.ufrgs.br/ensfis_ fernanda/arquivos/publicacoes/nathan_fernanda_ 区ii_epef_2010.pdf, acessado em 10/10/2013.

[12] A. Hipólito and H.E. Silveira, VIII ENPEC, Campinas, 2011. http://www.nutes.ufrj.br/abrapec/ viiienpec/resumos/R0237-1.pdf, acessado em $10 / 10 / 2013$.

[13] E. M. Miranda, A.R. Alves, M.L.M. Menten, D. Freitas, V.G. Zuin and A.H.C. Pierson, VIII ENPEC, Campinas, 2011. http://www.nutes.ufrj.br/ abrapec/viiienpec/resumos/R0292-1.pdf, acessado em 10/10/2013.

[14] E.R. Mozena and F. Ostermann, Uma revisão bibliográfica sobre a interdisciplinaridade no ensino das ciências da natureza. Artigo em fase de arbitragem, 2013.

[15] M. Arcà and M. Vicentini, International Journal of Scientific Education 3, 116 (1981).

[16] V. Lavaqui and I.L. Batista, Ciência \& Educação 13, 399 (2007)

[17] M.R.D. Kawamura, Ciência \& Ensino 2, 3 (1997).

[18] M.G. Bardeen and L.M. Lederman, Science 281, 178 (1998).

[19] V. Lavaqui and I.L. Batista, op. cit., p. 415.

[20] M.R.D. Kawamura, op. cit., p. 5. 